\title{
TGF-B1 antisense therapy modulates expression of matrix metalloproteinases in keloid-derived fibroblasts
}

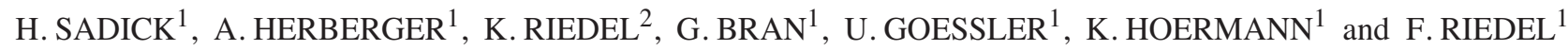 \\ ${ }^{1}$ Department of Otolaryngology, Head and Neck Surgery, University Hospital of Mannheim, University of Heidelberg, \\ Mannheim; ${ }^{2}$ Department of Hand, Plastic and Reconstructive Surgery, Burn Center, BG-Trauma Center, \\ Plastic and Hand Surgery at the University of Heidelberg, Ludwigshafen, Germany
}

Received January 24, 2008; Accepted March 18, 2008

\begin{abstract}
Transforming growth factor- $\beta 1$ (TGF- $\beta 1$ ) has been identified as an important regulator of wound healing. Recent developments in molecular therapy offer exciting prospects for the modulation of wound healing, specifically those targeting TGF- $\beta 1$. The purpose of this study was to analyze the effect of TGF- $\beta 1$ targeting on the expression of matrix metalloproteinases (MMPs) in fibroblasts cultured from earlobe keloids. The expression of MMP-2 and -9 in tissue samples from keloids was investigated by immunohistochemistry. The effect of TGF- $\beta 1$ targeting using antisense oligonucleotides on the expression of MMPs in keloid-derived fibroblasts was analysed by ELISA and multiplex RT-PCR. Immunohistochemical studies demonstrated an increased expression of MMP protein in tissue samples from keloids compared to normal human skin. Antisense TGF- 31 oligonucleotide treatment significantly downregulated MMP-9 secretion in vitro. In conclusion, TGF- $\beta 1$ antisense oligonucleotide technology may be a potential therapeutic option for the inhibition of proteolytic tissue destruction in keloids.
\end{abstract}

\section{Introduction}

Normal wound healing is regulated by a complex set of interactions within a network of profibrotic and antifibrotic cytokines and secreted proteins that ultimately lead to the restoration of injured tissue. Simplified, the process of wound healing can be subdivided into four overlapping stages: hemostasis, inflammation, proliferation and maturation. The initial physiologic response to an injury is hemostasis. The clotting cascade is activated, and fibrin polymerization occurs as a mature clot is formed together with aggregated platelets

Correspondence to: Dr Haneen Sadick, Department of Otolaryngology, Head and Neck Surgery, University Hospital of Mannheim, Theodor-Kutzer-Ufer, D-68135 Mannheim, Germany

E-mail: haneen.sadick@hno.ma.uni-heidelberg.de

Key words: fibroblasts, keloid, transforming growth factor- $\$ 1$, matrix metalloproteinases
(1). At that time, the inflammatory phase begins which is carried out mainly by macrophages. They secrete multiple cytokines and growth factors that stimulate chemotaxis of neutrophils into the wound and mediate various cellular activities (2). After 48-72 h, the healing process transitions into the proliferation phase which lasts 3-6 weeks. Fibroblasts are recruited into the wound to synthesize a framework of reparative tissue called the extracellular matrix (ECM). This granulation tissue is made of procollagen, elastin, proteoglycans and hyaluronic acid and forms a structural repair frame to bridge the wound and allow vascular ingrowth (2). Once the wound is closed, the immature scar transitions into the final maturation phase. In this phase, the abundant ECM is degraded, and the immature type III collagen of the early wound turns into the mature type I collagen. This balance of synthesis and degradation of scar components shifts into a downregulation of healing to allow the final scar to gain maximum organization and strength.

Keloids as well as hypertropic scars are fibroproliferative disorders of excessive wound healing. They represent a dysregulated response to cutaneous wounding which involves aberrant cytokine pathways or chronic overproduction of certain cytokines with uncontrolled matrix degradation and excessive deposition of ECM, especially collagen $(3,4)$. The collagen pattern is abnormally thick and shows irregular branched septal collagen bands. The lesions demonstrate overproduction of multiple fibroblast proteins suggesting either pathological persistence of wound healing signals or a failure of the appropriate downregulation of wound healing cells (5).

Tissue growth factors such as transforming growth factor- $\beta$ (TGF-B) are known to be the most potent growth factors involved in wound healing and are believed to be key regulators in the pathogenesis of keloids and other fibrotic conditions. Released by degranulating platelets at the site of injury, TGF- $\beta$ influences the inflammatory response, angiogenesis, re-epithelialization, ECM deposition and remodelling. Three isoforms, TGF- $\beta 1,-\beta 2$ and $-\beta 3$ exist. TGF- $\beta 1$ is thought to be profibrotic, whereas TGF- $\beta 3$ may have antifibrotic functions. The overproduction of the subtype TGF- $\beta 1$ is associated with an excessive deposition of scar tissue and fibrosis. TGF- $\beta$ modulates the expression of matrix metalloproteinases (MMPs), a family of zinc-dependent endopeptidases that are collectively capable of cleaving all 
the components of the ECM and the basement membrane (6). Expression of these MMPs in healthy tissues is low, but a special characteristic of keloid invasiveness is increased migratory activity associated with higher MMP-1 (interstitial collagenase) and MMP-2 (gelatinase-A) production (7). TGF- $\beta 1$ is known to induce expression of MMP-2, -9 and -13 in fibroblasts $(8,9)$, whereas MMP-1 expression is negatively regulated through SMAD3 and 4 (10).

TGF- 31 appears to be the growth factor most central to keloid pathogenesis, and it has a stimulatory effect on MMP expression. Thus, blocking this pathway may attenuate the fibroproliferative response of pathologic scarring and make its manipulation an attractive therapeutic strategy. In previous studies we demonstrated that the abrogation of TGF- $\beta$ in normal fibroblasts and keratinocytes resulted in decreased expression of MMPs $(11,12)$ and increased angiogenic activity (13). The aim of this study was to assess the effect of targeting TGF- 31 expression by antisense oligonucleotides on the expression of matrix metalloproteinases (MMP-2 and -9) in keloid-derived fibroblasts.

\section{Materials and methods}

Immunohistochemistry. Tissue specimens of keloids and normal control skin from the same patient were obtained, after written consent, from excised tissue during surgery and rapidly frozen in liquid nitrogen for later MMP identification. They were cut in $10-\mu \mathrm{m}$ cryostat sections, transferred onto glass slides, and air-dried overnight at room temperature. The sections were then stored at $-20^{\circ} \mathrm{C}$ until immunostaining. Immunohistochemistry for MMP-2 and -9 detection was performed by using a streptavidin-biotin complex procedure. Endogenous peroxidase was blocked with $0.3 \%$ hydrogen peroxide for $30 \mathrm{~min}$. The sections were washed with phosphate-buffered saline (PBS) and incubated with normal rabbit serum in PBS for $30 \mathrm{~min}$ at room temperature to block non-specific antibody reaction. The sections were then incubated overnight at $4{ }^{\circ} \mathrm{C}$ with the primary antibody. The slides were washed in several changes of PBS. The sections were then incubated with a peroxidase-conjugated secondary antibody (Dako, Hamburg, Germany). After being washed twice in PBS, the sections were treated with a streptavidinbiotin-peroxidase complex, and the peroxidase reaction was carried out using diaminobenzidine (DAB) (Dako) as the chromogen. The different antibodies were diluted to the desired concentrations in PBS. Controls were processed by omitting the primary antibody. Light microscopy was conducted using a Zeiss Axiophot microscope (Zeiss, Oberkochen, Germany).

Cell culture. For in vitro analysis, dermal fibroblasts isolated from keloids and normal controls were cultured in Falcon petri (Greiner, Germany) dishes at $37^{\circ} \mathrm{C}$ in a $5 \% \mathrm{CO}_{2}$ fully humidified atmosphere in serum-free Fibroblast Growth Medium (PromoCell, Heidelberg, Germany) supplemented with antibiotics. For antisense treatment, the medium from the cultures was aspirated and replaced with Dulbecco's modified minimum essential medium (DMEM) (Fisher Scientific Co., Pittsburgh, PA, USA) containing 5\% fetal calf serum (FCS) and antibiotics (Life Technologies, Inc., Gibco BRL,
Gaithersburg, MD, USA) followed by the addition of oligodeoxynucleotides.

Oligodeoxynucleotides. Phosphorothioated 14-mer oligodeoxynucleotides (ODNs) were synthesized on an Applied Biosystems 394 DNA synthesizer (Applied Biosystems Inc., Foster City, CA, USA) by means of B-cyanothylphosphoramidite chemistry to minimize degradation by endogenous nucleases. The antisense oligonucleotide (5'-CGA TAG TCT TGC AG-3') was directed against the translation start site and surrounding nucleotides of the human TGF- 11 cDNA. For negative control, the cells were treated by the addition of PBS or oligonucleotides (5'-GTC CCT ATA CGA AC-3') containing the same nucleotides in a scrambled order. The in vitro inhibitory effect of these antisense ODNs on TGF- 31 expression at both the mRNA and protein level in human cells was described previously (20). All experiments were performed with $3 \mu \mathrm{M}$ ODNs, respectively. To determine the effect of oligonucleotides on the expression of MMP mRNA, fibroblasts were plated at a density of $10^{5}$ cells/ microtiter well in 24-well polystyrene plates (Falcon). After $24 \mathrm{~h}$, the cells were rinsed twice with medium, and fresh TGF-ß1 oligo medium containing antisense or scrambled ODNs was added, followed by an incubation period of 48 and $72 \mathrm{~h}$.

Cytokine immunoassay. Cell culture supernatants were collected in sterile test tubes and stored at $-20^{\circ} \mathrm{C}$ until used. Then, cytokine (MMP-2, MMP-9) concentrations were determined by an ELISA technique (R\&D Systems, Wiesbaden, Germany). The system used a solid-phase monoclonal antibody and an enzyme-linked polyclonal antibody raised against recombinant cytokines. According to the manufacturer's directions, each ELISA assay measured $100 \mu 1$ of supernatant. All analyses and calibrations were carried out in duplicate. The calibrations on each microtiter plate included recombinant human cytokine standards provided in the kit. All concentrations were documented as $\mathrm{pg} / \mathrm{ml}$. The Student's t-test was used to calculate p-values. Differences were considered statistically significant at $p<0.05$. The SPSS software package for Windows was used to perform all statistical analyses.

$R T-P C R$. To isolated RNA from the fibroblasts grown in monolayer, the cells were directly lysed in the culture dish by the addition of $1 \mathrm{ml}$ RNA-Clean (RNA-Clean System, AGS, Heidelberg, Germany). After the addition of $0.2 \mathrm{ml}$ chloroform $/ 2 \mathrm{ml}$ of homogenate and centrifugation for $15 \mathrm{~min}$ at $12,000 \times \mathrm{g}\left(4^{\circ} \mathrm{C}\right)$, the aqueous phase was transferred to a fresh tube. After the addition of an equal volume of isopropanol and centrifugation for $15 \mathrm{~min}$ at $12,000 \times \mathrm{g}\left(4^{\circ} \mathrm{C}\right)$, the supernatant was removed from the RNA precipitate. The RNA pellet was washed twice with $70 \%$ ethanol by vortexing and subsequent centrifugation for $8 \mathrm{~min}$ at $7,500 \times \mathrm{g}\left(4^{\circ} \mathrm{C}\right)$. After drying, the RNA pellet was dissolved in DEPC water. The RNA was reverse transcribed (StrataScript First-Strand Synthesis Sytem, Stratagene, La Jolla, CA, USA) into cDNA using random oligonucleotide primers. Matrix metalloproteinase mRNA levels were measured in all three cell types using RT-PCR (MMP-CytoXpress Multiplex PCR Kit, 

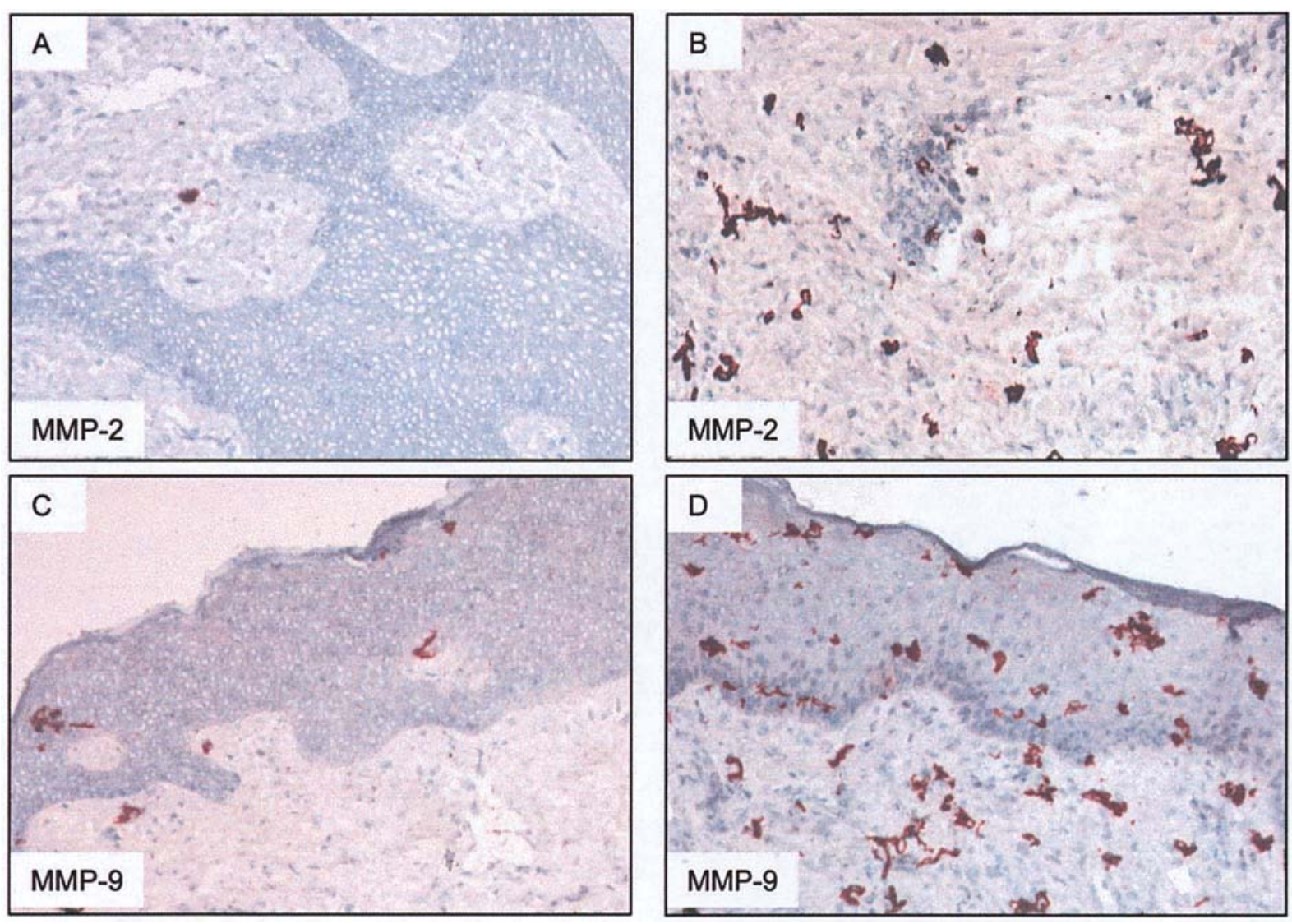

Figure 1. Immunohistochemstry of tissue samples from normal human control skin (left) and keloids (right). (A and B) Expression pattern of MMP-2 and (C and D) MMP-9.

BioSource, San Francisco, CA, USA) according to the manufacturer's instructions. To fractionate the MPCR DNA products, the MPCR products were mixed with $6 \mathrm{X}$ loading buffer and separated on a $2 \%$ agarose gel containing $0.5 \mathrm{mg} /$ $\mathrm{ml}$ ethidium bromide, visualized with UV light and recorded using a CCD camera. To test the quality of the cDNA, the kit includes primers for GAPDH. Results were obtained in two independent experiments.

\section{Results}

The presence of both MMP-2 and -9 proteins was found within the collagen and the fibroblasts of all the skin samples, but increased expression of both proteins was evident within the keloid samples (Fig. 1).

After $48 \mathrm{~h}$ of incubation with medium containing $3 \mu \mathrm{M}$ scrambled TGF- $\beta 1$ ODNs, the average level of MMP-2 was measured. MMP-2 secretion to the supernatant of keloidderived fibroblasts 48 and $72 \mathrm{~h}$ after treatment with TGF- $\beta 1$ antisense ODNs was significantly decreased compared to MMP-2 secretion after treatment with medium (control) or TGF-ß1 scrambled ODNs ( $\mathrm{p}<0.05)$ (Fig. 2A). Similar results were obtained for MMP-9 secretion from keloid-derived fibroblasts (Fig. 2B). The MMP-9 level was significantly decreased after 48 and $72 \mathrm{~h}$ of treatment with TGF-B1 antisense ODNs compared to the MMP-9 level after incubation with TGF-ß1 scramble ODNs or control medium $(\mathrm{p}<0.05)$.
Regarding expression of MMP-2 and -9 mRNA, the treatment of fibroblasts with TGF- $\beta 1$ antisense ODNs for 48 and $72 \mathrm{~h}$ did not result in a decrease in expression of MMP-2 mRNA compared to the cells that were treated with either scrambled oligonucleotides or with PBS. However, expression of MMP-9 mRNA decreased after the treatment of fibroblasts with TGF-ß1 antisense ODNs (Fig. 3).

\section{Discussion}

Keloids are skin abnormalities that are characterized by excessive deposition of collagen bundles in the dermis following cutaneous injury (14). Clinically, keloids differ from hypertrophic scars by their extension beyond the boundaries of the original injury (15), their failure to regress due to a failed activation of the remodelling phase, and a higher recurrence rate after excision in the head and neck (2). The prevalence of keloid formation is 5-15 times higher in African-Americans than in Caucasians, a racial distribution which is noted worldwide with darker-skinned people being more prone to keloid formation. In general, keloid formation tends to be regionally isolated to areas such as the chest and the earlobe, whereas the hand and feet are usually spared (2).

The treatment strategies for keloids such as intralesional steroids, cryosurgery, radiotherapy, pressure therapy, 5fluorouracil, silicone gel sheeting and excisional surgery continue to be used and debated $(16,17)$. The variety of 
A

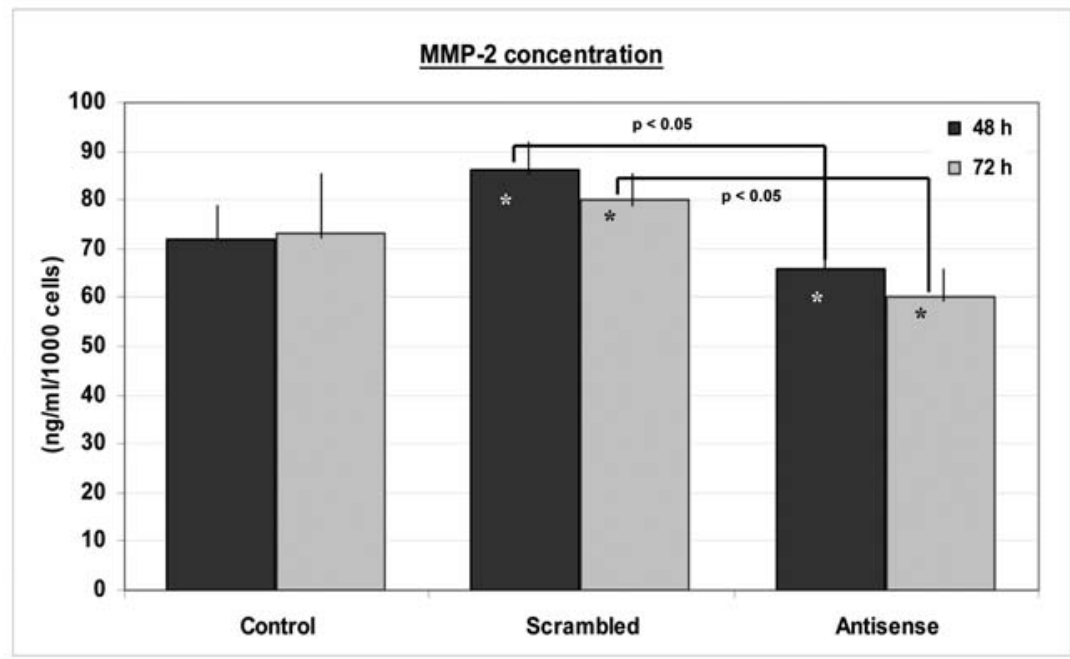

B

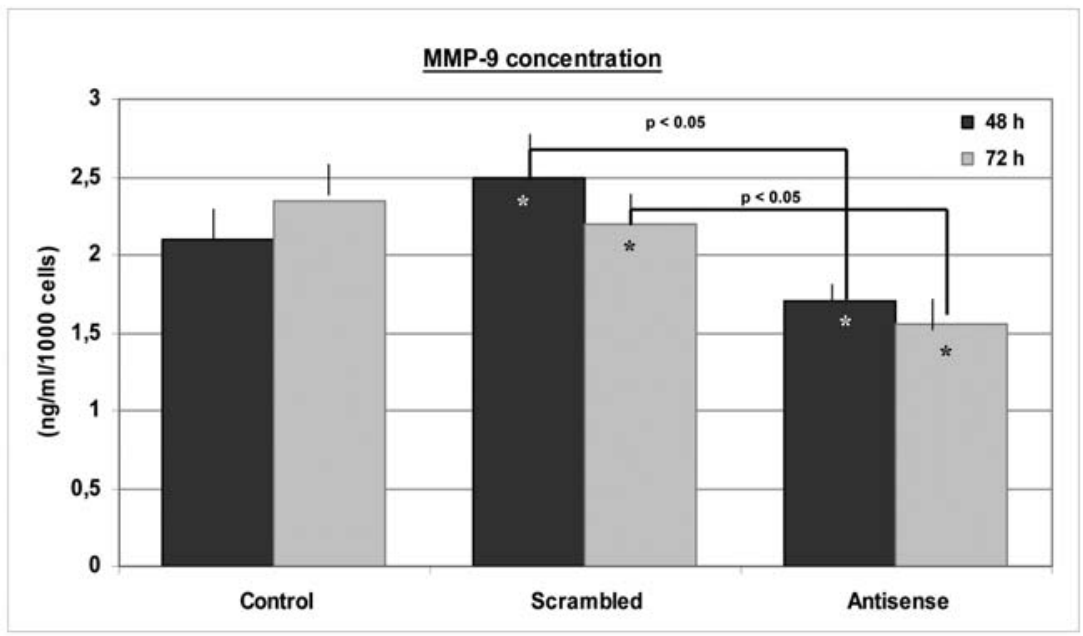

Figure 2. Cytokine secretion to the supernatant of human keloid-derived fibroblasts, 48 and $72 \mathrm{~h}$ after treatment with medium (control) or medium containing TGF- 11 antisense or scrambled ODNs. MMP-2 (A) and MMP-9 (B) were significantly decreased compared to the controls ( $\mathrm{p}<0.05$ ).
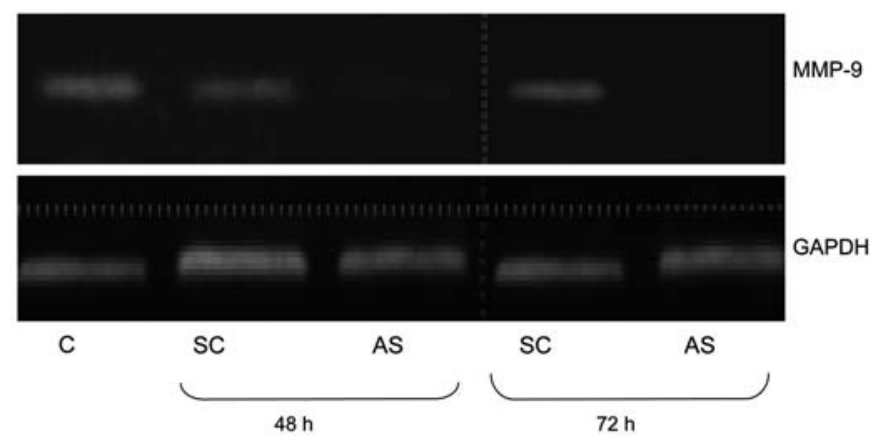

Figure 3. Expression of mRNA of MMP-9 in keloid-derived fibroblasts, 48 and $72 \mathrm{~h}$ after treatment with TGF- 31 antisense ODNs. C, control (PBS); SC, control (scrambled ODNs); AS, antisense ODNs.

different treatment strategies reflects the difficulty in treating keloids effectively.

During the last few decades, research has aimed to determine the molecular basis of wound healing and keloid pathogenesis. Gene therapy in this environment poses a particular challenge (18). Numerous models of gene delivery have been developed, including naked DNA application, viral transfection, high-pressure injection and liposomal delivery. The skin is an ideal candidate for genetic manipulations (19). It is easily accessible, rendering it easy to monitor for adverse reactions, and easy to transfect. The epidermis has a high turnover which provides an ideal situation for most gene transfer methods. The predominant cells of the skin, fibroblasts and keratinocytes, are easily harvested and cultured, allowing for testing in vitro and for use as vehicles in gene transfer. This has led to an increasing interest in the use of gene therapy in skin diseases, especially wound healing (20). The pivotal role of growth factors in the regulation of wound repair has led to the development of multiple molecular genetic approaches that mainly focus on stimulation and enhancement or abrogation of this protein group.

Transforming growth factor (TGF)- $\beta$ appears to be the growth factor most important to keloid pathogenesis. Increased understanding of the role of TGF- $\beta$ signalling in keloids and the characterization of the different TGF- $\beta$ subtypes make 
manipulation of TGF- $\beta$ an attractive therapeutic strategy. A number of studies have indicated that TGF- 11 induces keloid formation $(2,21)$. Some studies have suggested that keloid scarring may be caused by fibroblasts that secrete elevated levels of TGF- $\beta 1$, resulting in a TGF- $\beta 1$ overproduction by keloid tissue which is poorly regulated through normal autocrine signalling mechanisms (2). Lee et al demonstrated the increased expression of both TGF- $\beta 1$ and TGF- $\beta 2$ proteins in keloid fibroblasts relative to normal human dermal fibroblasts using Western blot analysis (22).

Not only does TGF- $\beta$ play a critical role in collagen synthesis but it is also a regulator of extracellular matrix (ECM) deposition in the maturation phase of wound healing (23). This role of TGF- $\beta$ becomes more evident in fibrotic diseases. The major pathogenetic feature of fibrosis is represented by excessive accumulation of collagen and extracellular matrix (ECM) leading to progressive organ dysfunction in the liver, lung, kidney or skin. Ask et al described this phenomenon as a disturbed balance between degradation and accumulation of ECM in favor of accumulation (24). In normal wound healing, matrix metalloproteinases (MMPs), a family of secreted and membraneanchored proteinases, are essential to the ECM maturation phase by removing devitalized tissue and by re-epithelializating cutaneous wounds $(25,26)$. Studies showed that temporally controlled expression of several distinct MMPs is associated with normal wound healing and ulcer repair $(27,28)$. The ECM of keloids is abnormal, with elevated levels of fibronectin and proteoglycans as well as MMPs which influence collagen architecture (29). Previous reports exist on keloids and MMP. Neely et al reported that MMP-2 activity was significantly increased in hypertrophic scars and keloids (30). Oriente and co-workers reported that TGF- $\beta 1$ induces upregulation of MMPs in keloid fibroblasts (31).

The present study demonstrated an increased expression of collagenases MMP-2 (gelatinase A) and MMP-9 (gelatinase B) in tissue samples of keloids and increased levels of MMP expression in keloid-derived fibroblasts compared to healthy skin. Although proteolysis of the extracellular matrix and its degradation is necessary for normal wound healing, such an uncontrolled state appears to be a pathogenic factor in keloids. Persistent MMP concentrations could be evidence of early chronification of these lesions indicating a molecular environment in keloids hostile for normal cell replication after injury. We thus assume a general malfunction of cellular wound healing processes in patients with keloids.

The prolonged treatment period and the complexity of treating keloids necessitate the need for a drug or treatment that promotes healing (18). Targeting TGF- $\beta$, the key regulator of wound healing, might affect cytokine expression patterns of cells involved in the process of wound healing $(32,33)$. Molecular biology has provided synthetic oligonucleotide sequences complementary to target genes, referred to as antisense. Antisense technology has as its basis the selective impairment of protein synthesis in the cytoplasm through the use of antisense ODN sequences. A small antisense DNA sequence to the start codon and slightly beyond hybridizes with the $5^{\prime}$ end of the mRNA, causing translation arrest (34-36). This provides a major tool for assessing gene expression and the function of the gene product $(37,38)$. In previous studies, topical application of antisense ODNs targeted to TGF- $\$ 1$ mRNA in skin wounds of mice resulted in a marked reduction of fibrosis associated with decreased expression of the TGF- 11 gene (39). Shah et al reported that the neutralizing antibody to TGF- $\beta$, when applied early to adult dermal wounds, reduced scarring (33). These results were confirmed by other studies, where the neutralizing antibody to TGF- $\beta$, reduced the fibrotic process in glomerulonephritis as well as in acute and chronic synovial inflammation $(40,41)$.

Our study demonstrated that the treatment of human keloid-derived fibroblasts with TGF- $\beta 1$ antisense ODNs in vitro efficiently downregulated MMP-9 expression but not MMP-2 expression. Although the TGF- 31 antisense therapy did not show downregulation of the mRNA MMP-2 expression, it did show a decreased secretion level of not only MMP-9 but also MMP-2 in the supernatants of keloid-derived fibroblasts. Thus, apart from MMP-9, the synthesis of MMP-2 does not seem to be influenced by TGF- 31 antisense ODNs where the secretion of MMP-2, similar to that of MMP-9, is significantly decreased in the supernatants of keloid-derived fibroblasts. Our report suggests that antisense TGF-ß31 ODNs may have a potential therapeutic role in the treatment of keloids. The potential for modulating gene expression by the use of antisense oligonucleotides has become increasingly important in recent years. This antisense technology has been extensively used in vitro and in vivo as a tool to study the regulatory mechanisms in biological processes and as potential therapeutic agents in cancer, viral infections and genetic disorders (42). The therapeutic application of antisense has resulted in advances in medicine. However, this potential therapeutic approach is dependent upon the degree of antisense stability, the rate of cellular uptake and accumulation of the antisense molecules, the selection of the proper target gene, the absence of effects on nontargeted genes, minimal toxicity of the antisense ODNs, structure and length of the antisense ODNs, and type and duration of treatment. The specificity of antisense is high since targeted mRNA can discriminate between antisense ODN sequences that differ by one or two bases (34-36). In recent studies, antisense oligonucleotides have been tested for toxicity and clinical activity in a phase I evaluation in patients with advanced cancer (43).

In summary, we demonstrated that antisense TGF- 11 ODN treatment downregulates MMP-2 mRNA expression in human keloid-derived fibroblasts. These results should be regarded as a further implication for the possible treatment of keloids.

\section{Acknowledgements}

The authors would like to thank Petra Prohaska, Department of Otolaryngology Mannheim, for her excellent technical assistance.

\section{References}

1. Kamamoto F, Paggiaro AO and Rodas A: A wound contraction experimental model for studying keloids and wound-healing modulators: Artif Organs 27:701-705, 2003.

2. Slemp AE, Kirschner RE, Bettinger DA, Yager DR, Diegelmann RF and Cohen IK: The effect of TGF- $B$ on keloid fibroblast proliferation and collagen synthesis. Plast Reconstr Surg 98: 827-833, 1996. 
3. Kuo YR, Wu WS, Jeng SF, Wang FS, Huang HC, Lin CZ and Yang KD: Suppressed TGF-beta1 expression is correlated with up-regulation of matrix metalloproteinase-13 in keloid regression after flashlamp pulsed-dye laser treatment. Lasers Surg Med 36: 38-42, 2005.

4. Sato M: Upregulation of the Wnt/beta-catenin pathway induced by transforming growth factor-beta in hypertrophic scars and keloids. Acta Derm Venereol 86: 300-307, 2006.

5. Slemp A and Kirschner RE: Keloids and scars: a review of keloids and scars, their pathogenesis, risk factors, and management. Curr Opin Pediatr 18: 396-402, 2006.

6. Wall SJ, Bevan D, Thomas DW, Harding KG, Edwards DR and Murphy G: Differential expression of matrix metalloproteinases during impaired wound healing of the diabetic mouse. J Invest Dermatol 119: 91-98, 2002.

7. Thielitz A, Vetter RW, Schultze B, et al: Inhibitors of dipeptidyl peptidase IV-like activity mediate antifibrotic effects in normal and keloid-derived skin fibroblasts. J Invest Dermatol 128: 855$866,2008$.

8. Ravanti L, Häkkinen L, Larjava H, Saarialho-Kere U, Foschi M, Han J and Kähäri VM: Transforming growth factor-beta induces collagenase- 3 expression by human gingival fibroblasts via p38 mitogen-activated protein kinase. J Biol Chem 274: 37292-37300, 1999.

9. Saed GM, Zhang W and Diamond MP: Effect of hypoxia on stimulatory effect of TGF-beta 1 on MMP-2 and MMP-9 activities in mouse fibroblasts. J Soc Gynecol Investig 7: 348-354, 2000.

10. Yuan W and Varga J: Transforming growth factor-beta repression of matrix metalloproteinase-1 in dermal fibroblasts involves Smad3. J Biol Chem 276: 38502-38510, 2001.

11. Philipp K, Riedel F, Germann G, Hormann K and Sauerbier M: TGF- $\beta$ antisense oligonucleotides reduce mRNA expression of matrix metalloproteinases in cultured wound-healing-related cells. Int J Mol Med 15: 299-303, 2005.

12. Philipp K, Riedel F, Sauerbier M, Hormann K and Germann G: Targeting TGF- $\beta$ in human keratinocytes and its potential role in wound healing. Int J Mol Med 14: 589-593, 2004.

13. Riedel K, Riedel F, Goessler UR, Germann G and Sauerbier M: TGF-beta antisense therapy increases angiogenic potential in human keratinocytes in vitro. Arch Med Res 38: 45-51, 2007.

14. Tuan TL and Nichter LS: The molecular basis of keloid and hypertrophic scar formation. Mol Med Today 4: 19-24, 1998.

15. Chen MA and Davidson TM: Scar management: prevention and treatment strategies. Curr Opin Otolaryngol Head Neck Surg 13: 242-247, 2005.

16. Pollack SV and Goslen JB: The surgical treatment of keloids. J Dermatol Surg Oncol 8: 827-833, 1982.

17. Murray JC: Keloids and hypertrophic scars. Clin Dermatol 12: 27-37, 1994.

18. Williams RL and Armstrong DG: Wound healing. New modalities for a new millennium. Clin Podiatr Med Surg 15: 117-128, 1998.

19. Riedel K, Riedel F, Goessler UR, Holle G, Germann G and Sauerbier M: Current status of genetic modulation of growth factors in wound repair. Int J Mol Med 17: 183-193, 2006.

20. Hernandez A and Evers BM: Functional genomics: clinical effect and the evolving role of the surgeon. Arch Surg 134: 1209-1215, 1999.

21. Younai S, Nichter LS, Wellisz T, Reinisch J, Nimni ME and Tuan TL: Modulation of collagen synthesis by transforming growth factor- $\beta$ in keloid and hypertrophic scar fibroblasts. Ann Plast Surg 33: 148-151, 1994.

22. Lee TY, Chin GS, Kim WJ, Chau D, Gittes GK and Longaker MT: Expression of transforming growth factor beta 1,2 and 3 proteins in keloids. Ann Plast Surg 43: 179-184, 1999.

23. Falanga V: Chronic wounds: pathophysiologic and experimental consideration. J Invest Dermatol 100: 721-725, 1993.
24. Ask K, Bonniaud P, Maass K, Eickelberg O, Margetts PJ, Warburton D, Groffen J, Gauldie J and Kolb M: Progressive pulmonary fibrosis is mediated by TGF-beta isoform 1 but not TGF-beta3. Int J Biochem Cell Biol 40: 484-495, 2008.

25. Agren MS: Matrix metalloproteinases (MMPs) are required for re-epithelialization of cutaneous wounds. Arch Dermatol Res 291: 583-590, 1999.

26. Pattison PS: The importance of reassessment to chronic wound care. Ostomy Wound Manage 47: 24-25, 2001.

27. Kähäri VM and Saarialho-Kere U: Matrix metalloproteinases in skin. Exp Dermatol 6: 199-213, 1997.

28. Soo C, Shaw WW, Zhang X, Longaker MT, Howard EW and Ting K: Differential expression of matrix metalloproteinases and their tissue-derived inhibitors in cutaneous wound repair. Plast Reconstr Surg 105: 638-647, 2000.

29. Al-Attar A, Mess S, Thomassen JM, Kauffman CL and Davison SP: Keloid pathogenesis and treatment. Plast Reconstr Surg 117: 286-300, 2006.

30. Neely AN, Clendening CE, Gardner J, et al: Gelatinase activity in keloids and hypertrophic scars. Wound Repair Regen 7: 166-171, 1999.

31. Oriente A, Fedarko NS, Pacocha SE, Huang SK, Lichtenstein LM and Essayan DM: Interleukin-13 modulates collagen homeostasis in human skin and keloid fibroblasts. J Pharmacol Exp Ther 292: 988-994, 2000.

32. Saito S, Trovato MJ, You R, Lal BK, Fasehun F, Padberg FT Jr, Hobson RW II, Duran WN and Pappas PJ: Role of matrix metalloproteinases 1,2, and 9 and tissue inhibitor of matrix metalloproteinase-1 in chronic venous insufficiency. J Vasc Surg 34: 930-938, 2001.

33. Shah M, Foreman DM and Ferguson MWJ: Neutralisation of TGF- $\beta 1$ and TGF- $\beta 2$ or exogenous addition of TGF- $\beta 3$ to cutaneous wounds reduces scarring. J Cell Sci 108: 983-1002, 1995.

34. Pirollo KF, Rait A, Sleer LS and Chang EH: Antisense therapeutics: from theory to clinical practice. Pharmacol Ther 99: 55-77, 2003

35. Wacheck V: Oligonucleotide therapeutics - an emerging novel class of compounds. Wien Med Wochenschr 156: 481-487, 2006.

36. Wraight CJ and White PJ: Antisense oligonucleotides in cutaneous therapy. Pharmacol Ther 90: 89-104, 2001.

37. Schiavone N, Donnini M, Nicolin A and Capaccioli S: Antisense oligonucleotide drug design. Curr Pharm Des 10: 769-784, 2004.

38. Mirabelli CK, Bennett CF, Anderson $\mathrm{K}$ and Crooke ST: In vitro and in vivo pharmacologic activities of antisense oligonucleotides. Anticancer Drug Des 6: 647-661, 1991.

39. Choi BM, Kwak HJ, Jun CD, Park SD, Kim KY, Kim HR and Chung HAT: Control of scarring in adult wounds using antisense transforming growth factor-beta 1 oligodeoxynucleotides. Immunol Cell Biol 74: 144-150, 1996.

40. Wahl SM, Allen JB, Costa GL, Wong HL and Dasch JR: Reversal of acute and chronic synovial inflammation by antitransforming growth factor beta. J Exp Med 177: 225-230, 1993.

41. Border WA and Ruoslahti E: Transforming growth factor-beta 1 induces extracellular matrix formation in glomerulonephritis. Cell Differ Dev 32: 425-431, 1990.

42. Field AK and Goodchild J: Antisense oligonucleotides: rational drug design for genetic pharmacology. Exp Opin Invest Drugs 4: 799-821, 1995 .

43. Nemunaitis J, Holmlund JT, Kraynak M, Richards D, Bruce J, Ognoskie N, Kwoh TJ, Geary R, Dorr A, Von Hoff D and Eckhardt SG: Phase I evaluation of ISIS 3521, an antisense oligodeoxynucleotide to protein kinase C-alpha, in patients with advanced cancer. J Clin Oncol 17: 3586-3595, 1999. 